Journal of Applied Pharmaceutical Science Vol. 5 (08), pp. 006-010, August, 2015

Available online at http://www.japsonline.com

DOI: $10.7324 / \mathrm{JAPS} .2015 .50802$

ISSN 2231-3354 (cc) BY-NC-SA

\title{
Antioxidant and tyrosinase inhibition activities of Eurycoma longifolia and Swietenia macrophylla
}

\author{
Wan Nur Atiqah Wan Hassan ${ }^{1}$, Razauden Mohamed Zulkifli ${ }^{*}$, Farediah Ahmad ${ }^{2}$, Mohd Azizi Che Yunus ${ }^{3}$ \\ ${ }^{1}$ Department of Bioscience and Health Sciences, Faculty of Bioscience and Medical Engineering, Universiti Teknologi Malaysia, 81310 , Skudai, Johor, \\ Malaysia. ${ }^{2}$ Department of Chemistry, Faculty of Science, Universiti Teknologi Malaysia, 81310, Skudai, Johor, Malaysia. ${ }^{3}$ Department of Chemical \\ Engineering, Faculty of Chemical Engineering, Universiti Teknologi Malaysia, 81310, Skudai, Johor, Malaysia.
}

\begin{tabular}{|c|c|}
\hline ARTICLE INFO & ABSTRACT \\
\hline Article history: & \multirow{9}{*}{$\begin{array}{l}\text { Extract from plants have been reported to contain valuable bioactive compounds that have potential in promoting } \\
\text { antioxidant activity. The present study was aimed to investigate the extracts of two plants available in Southeast } \\
\text { Asia, Eurycoma longifolia and Swietenia macrophylla for their primary metabolite contents, phenolic contents, } \\
\text { antioxidant and anti- tyrosinase activity. Two types of solvents were utilised in the extraction process of both } \\
\text { plants. Ethyl acetate found to be a better solvent for isolation of primary metabolite compound compared to } \\
\text { methanol. For Folin-Ciocalteu assay, methanol extract of Swietenia macrophylla possed higher phenolic content } \\
\text { while for Eurycoma longifolia, ethyl acetate extract had higher phenolic content. In DPPH assay, the radical } \\
\text { scavenging activity of extracts were strongly correlated to the total phenolic content based on the percentage of } \\
\text { DPPH radical scavenging of each extracts }(p<0.05) \text {. In tyrosinase inhibition assay, the activity of each extracts } \\
\text { were very low compared to standard Kojic acid. It was assumed that, the ability of plant extracts to inhibit } \\
\text { tyrosinase are partly contributed by antioxidant potential of the extracts }(p<0.01) \text {. }\end{array}$} \\
\hline 15 & \\
\hline $\mathrm{Re}$ & \\
\hline & \\
\hline Available & \\
\hline Key wo & \\
\hline Eurycoma longifolia, & \\
\hline Swietenia macrophylla, & \\
\hline $\begin{array}{l}\text { phenolic content, antioxidant, } \\
\text { tyrosinase inhibition }\end{array}$ & \\
\hline
\end{tabular}

\section{INTRODUCTION}

Reactive oxygen species (ROS) is defined as oxygen containing molecules that are more reactive than triplet state oxygen in the air (Noguchi and Niki, 1999). Generally ROS are the form of reactive free radicals contained one or more unpaired electron (Halliwell et al., 1995). Reactive oxygen species (ROS) were produced by human body to carry out physiological functions (Noguchi and Niki, 1999). However, ROS can cause oxidative stress and involved in the pathology of degenerative diseases and conditions such as artherosclerosis, cancer, rheumatoids arthritis and conditions of neurodegeneration, aging and inflammation (Parvathy et al., 2014). Continuous exposure of skin to direct ultraviolet (UV) from sunlight also make it vulnerable to oxidative stress and can cause pre-matured ageing and hyperpigmentation. These problems may affect the quality of patient's life (Kim et al., 2008; Heo et al., 2009).

\footnotetext{
* Corresponding Author

Razauden Mohamed Zulkifli, Department of Bioscience and Health Sciences, Faculty of Bioscience and Medical Engineering, Universiti Teknologi Malaysia, 81310, Skudai, Johor, Malaysia Email: razauden@fbb.utm.my
}

Medicinal plants have played an important role in the development and progress of many modern drugs, directly and indirectly (Parvathy et al., 2014). Several numbers of modern drugs have been developed from medicinal plants due to their rich sources of bioactives (Gragg and Newman, 2002). The medicinal effects of such plants are due to secondary metabolites, such as phenolic compounds, carotenoids, phytic acid, flavonoids, vitamins and alkaloids. Secondary plants metabolites, especially those that constitute medicinal foods, are being actively researched for antioxidant and biological effects (Parvathy et al., 2014; Gragg and Newman, 2002).

Eurycoma longifolia and Swietenia macrophylla are two plants that can be found commonly in Malaysia and Southeast Asia. E. longifolia from the family Simaroubaceae contains wide range of chemical compounds mostly from the roots. Some of them include alkaloids, quassinoids, quassinoids diterpenoids, eurycomaoside, tirucallane- type triterpenes, squalene derivatives, biphenylneolignans, eurycolactone, laurycolactone and eurycomalactone (Bhat and Karim, 2010). The plant extracts have been proved for its antimalarial, anticancer, anti-diabetic, antimicrobial, aphrodisiac and anti-pyretic activities (Bhat and Karim, 2010; Kuo et al., 2003). 
While, S. macrophylla from the family of Maliaceae consists of various chemical constituents include alkaloids, terpenoids, antraquinoes, cardiac glycosides, saponins, phenols, flavonoids, volatile oils, phospholipids and long chain unsaturated acid (Sahgal et al., 2011; Bacsal et al., 1997). The seeds have been used traditionally as cure for various ailments. The seed have been used for abortion medicine, leishmaniasis, cancer, amoebiasis, malarial, hypertension, diabetes, cough, chest pain and intestinal parasitism (Bacsal et al., 1997). Previously, there are limited studies that report on antioxidant activity of both plants. Therefore this study were aimed to investigate the ability of Eurycoma longifolia roots and Swietenia macrophylla seeds to scavenge the free radical that cause oxidation.

\section{MATERIALS AND METHODS}

\section{Plant material}

Eurycoma longifolia roots were obtained from local herbs supplier, Johor, Malaysia while Swietenia macrophylla seeds originally from Indonesia were obtained from local supplier, Kedah, Malaysia. All samples were air dried under room temperature before being grounded.

\section{Chemicals and reagents}

Analytical grade methanol, ethanol, ethyl acetate, DMSO (dimethyl sulfoxide), were bought from Merck (Darmstadt, Germany). L-DOPA (L-3, 4-dihydroxyphenylalanine) were ordered from Sigma- Aldrich (China). Bradford reagent, Bovine Serum Albumin Fraction V, glucose, gallic acid, DPPH (2,2diphenyl-1- picrylhydrazyl), Sodium carbonate $\left(\mathrm{NaCO}_{3}\right)$, Anthrone analytical standard, Tyrosinase, Kojic acid, L-ascorbic acid were purchased from Sigma- Aldrich (USA). Potassium hydrogen phosphate and Potassium dihydrogen phosphate were from Qrec and Folin-Ciocalteu Reagent was from Fluka Biochemika.

\section{Preparation of the extract}

The successive extraction methods utilized extraction technique done by Agraval et al. (2012). The plants were dried under normal environmental condition and ground to powder. The extraction of the powdered plant was carried out with the following solvents successively; 1) ethyl acetate 2) methanol in the increasing order of their polarity. The powder was dried before employing the solvent of higher polarity. Each extract was then concentrated using rotary evaporator at 40 to $50^{\circ} \mathrm{C}$.

\section{Estimation of primary metabolic contents Estimation of total protein}

Total protein content of samples were estimated by Bradford assay. This assay was performed in a 96 microwell plate. Bovine serum albumin (BSA) was used as standard. $5 \mu \mathrm{L}$ of samples and BSA were added to separate well in plate while $5 \mu \mathrm{L}$ of solvent was added in blank well. $250 \mu \mathrm{L}$ of Bradford reagent were added to each well and mix approximately for $30 \mathrm{~s}$. The samples were incubated for 5 to $45 \mathrm{~min}$. Then, the absorbances were measured at $595 \mathrm{~nm}$. The net absorbance vs. standard concentration were plotted. The protein concentration of the samples were analyzed against standard curve of BSA.

\section{Estimation of total polysaccharide}

Total polysaccharide estimation was performed using anthrone method as referred to Hussain et al. (2008). Glucose was used as the standard. The sample was dissolved in $80 \%$ hot ethanol in centrifuge tube and then vortex. The tube was centrifuged at $2700 \mathrm{rpm}$ for $10 \mathrm{~min}$ and was repeated for several times until washing did not give color to anthrone reagent. The dried pellet was extracted at $0^{\circ} \mathrm{C}$ for $20 \mathrm{~min}$ with distilled water and $25 \% \mathrm{HCl}$. The tube was again centrifuged to get the supernatant. $0.1 \mathrm{~mL}$ supernatant was transferred to test tube and made the volume to 1 $\mathrm{mL}$ with distilled water. Then anthrone reagent were added. The tube was heated in boiling water for $8 \mathrm{~min}$ and cooled rapidly. Then intensity of green color was measured at $630 \mathrm{~nm}$ against blank. Concentration of the glucose in samples were calculated from the linear regression equation, obtained from the standard curve. Polysaccharide contents were then calculated by multiplying the glucose contents with factor 0.9 .

\section{Measurement of total phenolic content (TPC)}

Total phenolic content of extracts were determined according the methods described by Folin and Ciocalteu, (1927). Gallic acid was used as standard. Tested sample was freshly prepared using DMSO. One tenth of the sample was diluted with distilled water to make it into $1 \mathrm{~mL}$. Each sample was added with $50 \mu \mathrm{L}$ Folin-Ciocalteu reagent and vortex thoroughly for $2 \mathrm{~min}$. Each mixture was added with $500 \mu \mathrm{L}$ of $5 \%$ (w/v) $\mathrm{Na}_{2} \mathrm{CO}_{3}$ and diluted with distilled water until final volume of $4 \mathrm{~mL}$. The mixture was incubated for $1 \mathrm{~h}$ in dark at room temperature. The absorbance was measured at $765 \mathrm{~nm}$. Total phenolic content was analyzed against Gallic acid calibration curve standard.

\section{Free radical scavenging activities}

2,2-diphenyl-1-picrylhydrazyl (DPPH) assay was carried out according to the method described by Brand-Williams et al. (1995). The assay was performed in 96 microwell plate. An aliquot of serially diluted samples $(100 \mu \mathrm{L})$ was added with $100 \mu \mathrm{L}$ of $0.04 \%$ (w/v) DPPH reagent to give final volume of $200 \mu \mathrm{L}$ equally. The plate was gently shaken to ensure thorough mixing before being incubated in dark for $30 \mathrm{~min}$ at room temperature. The absorbance was measured at $515 \mathrm{~nm}$ against blank. The percentage of DPPH inhibition was calculated using following formula:

Percentage of inhibition $=\left[\left(\right.\right.$ Absorbance $_{\text {control }}$ Absorbance $\left._{\text {sample }}\right) /$ Absorbance $\left._{\text {control }}\right] \times 100 \%$

The percentage of DPPH scavenging activity versus concentration of tested sample was plotted. The results were expressed in $\mathrm{IC}_{50}$ denoted to be the concentration of tested sample which be able to inhibit DPPH reagent by 50\%. Ascorbic acid was used as positive reference compound in the test. 


\section{Tyrosinase inhibitory activities}

Tyrosinase inhibitory activity was determined spectrophotometrically as described by Lim et al. (2009) using LDOPA as a substrate. Stock solution of extracts, kojic acid (positive reference compound), $100 \mathrm{unit} / \mathrm{mL}$ of tyrosinase and 2.5 $\mathrm{mM}$ of L-DOPA were freshly prepared. Tyrosinase stock solution was prepared by dissolving mushroom tyrosinase in $0.1 \mathrm{M}$ phosphate buffer (pH6.8). The total volume in test well was 200 $\mu \mathrm{L}$ that consist of $40 \mu \mathrm{L}$ of test samples, $80 \mu \mathrm{L}$ of $0.1 \mathrm{M}$ phosphate buffer, $40 \mu \mathrm{L}$ of tyrosinase solution and $40 \mu \mathrm{L}$ of L-DOPA. Each sample was accompanied by a blank well without tyrosinase solution and sample solvent was used as a replacement for test sample in control well. After 30 min incubation, the dopachrome formation was measured at wavelength $515 \mathrm{~nm}$ with $655 \mathrm{~nm}$ as a reference using spectrophotometric micro-plate reader. The percentage of tyrosinase inihibition was calculated as follows:

Percentage of inhibition $=\left[\left(\right.\right.$ Absorbance $_{\text {control }}-$ Absorbance $\left._{\text {sample }}\right) /$ Absorbance $\left._{\text {control }}\right] \times 100 \%$

\section{Statistical analysis}

The experiments were performed in triplicate from three independent experiments $(n=9)$. The statistical evaluation was performed by using SPSS Statistics version 16.0. The data were subjected to statistical analysis of one way ANOVA (Analysis of Variance). A value of $p<0.05$ was considered as significant value of the analyzed data.

\section{RESULTS AND DISCUSSIONS}

\section{Primary metabolites concentration}

Primary metabolites are compounds that commonly found in plant kingdom and being synthesized for important functions such as growth, development, reproduction and metabolisms. Some primary metabolites are precursors for the synthesis of secondary metabolites. Therefore, it is important to know the content of primary metabolites as it may contribute to plant's biological properties. In this study, the ethyl acetate and methanol extracts of E. longifolia and S. macrophylla were examined for their protein and polysaccharide contents.

Proteins are of great nutritional value and are involved directly in the chemical processes crucial for life. The protein content of most plants is low (Voet et al., 2008). Total protein content was estimated using Bradford assay. Bradford assay is very fast, fairly accurate and samples that are out of range can be retested within minutes (Bradford, 1976). Total protein contents of the samples were estimated using linear regression equation $(\mathrm{Y}=$ $0.2462 \mathrm{x}-0.0081, \mathrm{R}^{2}=0.9832$ ), which was obtained from calibration curve of Bovine Serum Albumin (fraction V).

Carbohydrates are important constituents of all living things and are divided into four major groups which are monosaccharides, disaccharides, oligosaccharides and polysaccharides (Voet et al., 2008).Anthrone reagent was used to estimate the total polysaccharide in plant extracts. In the test, a green color was produced when carbohydrates are heated with anthrone in acid solution (Yemm and Willis, 1954). Principally, the sample is treated with $80 \%$ alcohol to remove sugars and then starch is extracted with $25 \%$ Hydrochloric acid $(\mathrm{HCl})$. In hot acidic medium starch is hydrolyzed to glucose and dehydrated to hydroxymethyl furfural. This compound forms a green color product with Anthrone reagent (Dreywood, 1946; Yemm and Willis, 1954).The total polysaccharide contents of the samples were estimated by linear regression equation $(\mathrm{Y}=0.4224 \mathrm{x}+$ $0.0063, R^{2}=0.9981$ ), which was obtained from the standard curve of glucose.

Table 1: Primary metabolite concentration of samples.

\begin{tabular}{ccc}
\hline Sample & $\begin{array}{c}\text { Total protein } \\
\text { concentration }(\boldsymbol{\mu g} / \mathbf{m L})\end{array}$ & $\begin{array}{c}\text { Total polysaccharide } \\
\text { concentration }(\boldsymbol{\mu} \mathbf{g} / \mathbf{m L})\end{array}$ \\
\hline EL EA & $442 \pm 0.010$ & $253 \pm 0.001$ \\
EL MeOH & $370 \pm 0.003$ & $111 \pm 0.001$ \\
SM EA & $173 \pm 0.022$ & $129 \pm 0.004$ \\
SM MeOH & $116 \pm 0.008$ & $109 \pm 0.001$ \\
\hline
\end{tabular}

Data represent mean of three independent experiment $(n=9) \pm$ S.E.M. The differences between the samples were statistically significant $(p<0.05)$ for both total protein and total polysaccharide content test.

Different extraction solvents of the plant extract exhibited different contents of total proteins and total polysaccharides. This statement was supported by Hussain et al. (2008). The results indicated that protein and polysaccharide content in the extracts were less varied between solvent. The concentration of protein and polysaccharide are slightly higher in ethyl acetate extracts for both plants. Ethyl acetate which is a semi polar solvent was found to be a better extractive solvent of the primary metabolite contents of the plants than methanol.

\section{Total phenolic content}

As described by Rispail et al. (2005), phenolics are a large and diverse group of molecules, which includes many different families of aromatic secondary metabolites in plants. Folin-Ciocalteu assay is commonly used to determine the present of total phenolic contents in sample. In this assay, Gallic acid was used as a standard due to its high reduction ability. The total phenolic content in the samples were expressed as Gallic acid equivalent (GAE). The expression was determined from the linearity of the Gallic acid regression of calibration curve $\mathrm{Y}=$ $0.0013 x+0.0079, R^{2}=0.9995$.

Table 2: Total phenolic content of samples.

\begin{tabular}{cc}
\hline Sample & Total phenolic content $(\mathbf{m g}$ (GAE)/g dried material) \\
\hline EL EA & $52.74 \pm 0.23$ \\
EL MeOH & $30.85 \pm 0.41$ \\
SM EA & $11.20 \pm 0.32$ \\
SM MeOH & $24.53 \pm 0.50$ \\
\hline
\end{tabular}

Data represent mean of three independent experiment $(n=9) \pm$ S.E.M. The differences between the samples were statistically significant $(p<0.05)$.

In general, each extract was capable of extracting the phenolic compounds. Different types of solvents have different capacities for extracting out the phenolics substances thus different solvent with varying polarities lead to the different results. High polarity (polar protic) solvents may increase the yield of extracting 
phenolic contents. However, polar aprotic solvents may somehow have wide coverage in extracting polar and non- polar compounds, while non- polar solvents are best in dissolving only non- polar compounds.

Phenolics content were evaluated by the reduction ability of phenolics functional group. Reduction process of phenolics content then will change its colour to blue. The increment of phenolics content was shown by increasing of dark in colour present the high ability of antioxidant activities. As described by Manach et al. (2004), besides types of solvent, environmental factors such as types of soil, rainfall and exposure to sun also act as major factor that effect the phenolics content of plant extracts. Hence, different types of plant exhibit different total phenolic content.

\section{Free Radical Scavenging Activity (DPPH Assay)}

Free radical scavengers are defined as the compound's ability of donating electrons or hydrogen atoms in order to inhibit a free radical mechanism (Halliwell et al., 1995). The scavenging properties of antioxidants are often associated with their ability to form stable radicals. The DPPH assay measures the ability of sample to donate hydrogen to the DPPH radical resulting in bleaching of DPPH solution (Prabhune, 2013).

Table 3: Free radical scavenging capacities of the extracts measured by DPPH assay.

\begin{tabular}{ccc}
\hline Samples & $\begin{array}{c}\text { Percentage of inhibition }(\boldsymbol{\%}) \text { at } \\
\mathbf{5 0 0} \boldsymbol{\mu g} / \mathbf{m L}\end{array}$ & $\mathbf{I C}_{\mathbf{5 0}}(\boldsymbol{\mu g} / \mathbf{m L})$ \\
\hline EL EA & $74.04 \pm 2.19$ & 127 \\
EL MeOH & $71.22 \pm 2.30$ & 150 \\
SM EA & $30.30 \pm 1.63$ & $\mathrm{ND}$ \\
SM MeOH & $56.82 \pm 2.67$ & 200 \\
Ascorbic acid & $98.24 \pm 0.08$ & 1.2 \\
\hline
\end{tabular}

Data represent the percentage of inhibition \pm S.E.M and $\mathrm{IC}_{50}$ value of three independent experiments $(n=9)$. ND denotes not- detected. The difference in the DPPH radical scavenging capacity between samples was statistically significant $(\mathrm{p}<0.05)$

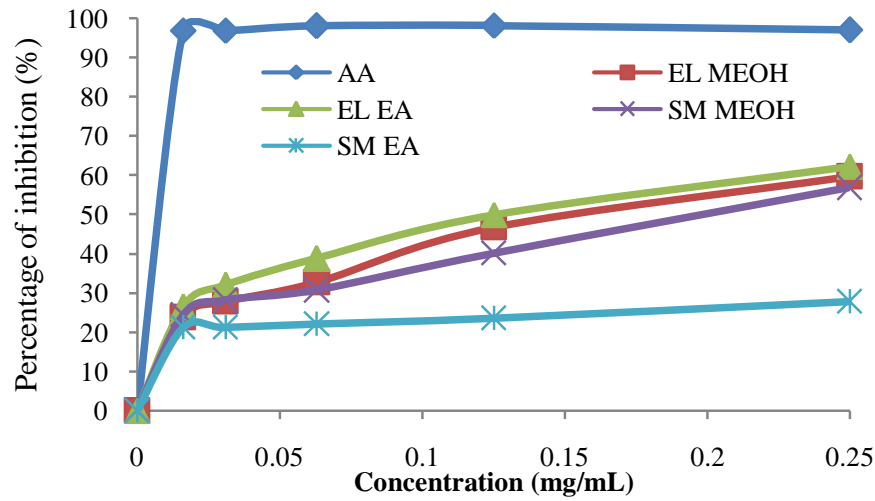

Fig. 1: Percentage of inhibition of extracts in DPPH assay. Values are represented as mean $(n=3) . A A=$ Ascorbic acid; $\mathrm{EL} \mathrm{MEOH}=$ methanol extract of E. longifolia; EL EA= ethyl acetate extract of E. longifolia; SM MEOH= methanol extract of $S$. macrophylla; SM EA= ethyl acetate extract of $S$. macrophylla.

Generally, all extracts showed an effective free radical scavenging activity based on their percentage of radical scavenging activity at $500 \mu \mathrm{g} / \mathrm{mL}$. All extracts reduced the DPPH free radical in dose dependent manner. However, ascorbic acid showed more powerful radical scavenging activity as its $50 \%$ inhibition with the lowest concentration obtained $(1.2 \mu \mathrm{g} / \mathrm{mL})$. Synthetic ascorbic acid was used as reference standard as it is the most well-known antioxidant. Ascorbic acid is the electron donor and this property accounts for all its known functions (Padayatty et al., 2003). The ability of the samples to scavenge the free radical was corresponding to their total phenolic content $(p<0.05)$. This statement was also reported by de Oliveira and Pinheiro (2012). The mechanisms in which the phenolic compounds exhibit antioxidant ability comprises of mechanism of scavenging free radicals, chelating transition metals and inhibiting the enzyme involved in free radical production (Yang et al., 2001; Aruoma, 2002; Hensley et al., 2004).

\section{Tyrosinase Inhibition Assay}

Normally, antioxidant agent posses tyrosinase inhibitory properties. Tyrosinase plays an important role in melanogenesis to synthesize melanin (Chang, 2009). Melanin is a dark molecular pigment that gives the color to hair, skin and other tissue and act as protective barrier against UV radiation. However, buildup of an abnormal amount of melanin in different specific part of the skin results in the formation of freckles or melasma (Chang, 2009).

Hence, further investigation on tyrosinase inhibition of these extracts were conducted. In this study, we investigated the direct tyrosinase inhibition mechanism in term of dopachrome formation. We utilized the tyrosinase from mushroom and LDOPA as the substrate to identify the ability of samples to inhibit tyrosinase enzymes.

Table 4: Percentage of tyrosinase inhibition of the extracts at concentration 1 $\mathrm{mg} / \mathrm{mL}$

\begin{tabular}{cc}
\hline Samples & Percentage of inhibition (\%) \\
\hline KA & $95.98 \pm 0.39$ \\
EL EA & $44.54 \pm 2.26$ \\
EL MeOH & $32.81 \pm 0.69$ \\
SM EA & $14.44 \pm 2.45$ \\
SM MeOH & $15.95 \pm 1.27$ \\
\hline
\end{tabular}

Data represent percentage of tyrosinase inhibition of three independent experiments $(n=9) \pm$ S.E.M. The differences between the samples were statistically significant $(\mathrm{p}<0.05)$.

Kojic acid standard had the strongest ability to inhibit the activity of tyrosinase. Kojic acid $\left(\mathrm{C}_{6} \mathrm{H}_{6} \mathrm{O}_{4}\right)$ or also known as5-hydroxy-2(hydroxymethyl)-4-pyrone is a well-known skin whitening agent or inhibitor of the pigment formation in animal tissues and plants. It also has been widely used as cosmetic material to lighten the skin, as food preservatives to control the change of color of substances and also applied on fruit that has been cut to prevent oxidative browning of fruits. Different solvents used exhibit different capability to inhibit tyrosinase reaction for both plants. In this study, the ability of the samples in inhibiting the tyrosinase were corresponding to their antioxidant properties $(p<0.01)$. It was reported by several studies in which, the ability of plant extracts to inhibit tyrosinase are partly contributed by antioxidant potential of the extract (Chan et al., 2008; Mazlan et al., 2013). 


\section{CONCLUSION}

In this present study, antioxidant activity of Eurycoma longifolia and Swietenia macrophylla extracts were strongly correlated to their total phenolic content $(p<0.05)$. The extracts also exhibit a little activity in inhibiting the enzyme tyrosinase that catalyse pigmentation process. Further studies should be done in order to identify and isolate the phenolic compounds that highly contribute to the antioxidant's ability of the extracts. It is relevant to develop an antioxidant agent from plant sources as it is consumers friendly and posses low side effect compared to synthetic product. In addition, an antioxidant agent that posses antityrosinase properties that may help in reducing the hyperpigmentation problem may also contribute to the cosmetic field.

\section{COMPETING INTERESTS}

The authors declared no potential conflicts of interest.

\section{REFERENCES}

Noguchi N, Niki E. 1999. Chemistry of Active Oxygen Species and Antioxidants. In: Papas AM, ed. Antioxidant Status in Diet, Nutrition and Health. USA: CRC Press, Inc., Boca Raton, FL 2-20.

Halliwell B, Murcia MA, Chirico S, Aruoma OI. Free radicals and antioxidants in food and in vivo: what they do and how they work. Critical Reviews in Food Science and Nutrition, 1995; 35:7-20.

Parvathy R, Mohanlal S, Pushpan C, Helen A, Jayalekshmy A. Antioxidant properties, anti- inflammatory effects and bioactive constituents of the Indian medicinal rice Njavara yellow compared with staple varieties. Food Sci Biotechnol, 2014; 23: 1379-1388.

Kim YJ, Kang KS, Yokozawa T. The anti- melanogenic effect of pycnogenol by its anti- oxidative actions. Food Chem Toxicol, 2008; 46: 2466-2471.

Heo SJ, Ko SC, Cha SH, Kang DH, Park HS, Choi YU, Kim D, Jung WK, Jeon YJ. Effect of phlorotannins isolated from Ecklonia cava on melanogenesis and their protective effect against photooxidative stress induced by UV- B radiation. Toxicol In Vitro, 2009; 23: 1123-1130.

Chang TS. An Updated Review of Tyrosinase Inhibitors. Int J Mol Sci, 2009;10: 2440-2475.

Cragg GM, Newman DJ. Chemical diversity: a function of biodiversity. Trends Pharmacol Sci, 2002; 23: 404-405.

Bhat R, Karim AA. Tongkat Ali (Eurycoma longifolia Jack): A review on its ethnobotany and pharmacological importance. Fitoterapia, 2010; 669- 679.

Kuo PC, Shi LS, Damu AG, Su CR, Huang CH. Cytotoxic and antimalarial $\beta$-carboline alkaloids from the roots of Eurycoma longifolia. J Nat Prod, 2003; 66: 1324-1327.

Sahgal G, Ramanathan S, Sasidharan S, Mordi MN, Ismail S, Mansor SM. In vitro and in vivo anticandidal activity of Swietenia mahogani methanolic seed extract. Tropical Biomed, 2011; 28: 132-137.

Bacsal K, Chavez L, Diaz I, Espina S, Javillo J, Manzanilla H, Motalban J, Panganiban C, Ro Driguez A, Sumpaico C, Talip B, Yap S. The effect of Swietenia mahogani (Mahogany) seed extract on indomethacin- induced gastric ulcers in female Sprague- Dawley rats. Acta medica Philippina, 1997; 33: 127-139.

Agraval M, Agrawal Y, Hankar P, Patil A, Vyas J, Kelkar A. Phytochemical and HPTLC studies of various extracts of Annona squamosa (Annonaceae). Int J Pharma Tech Res, 2012; 4: 364-368.
Hussain K, Ismail Z, Sadikun A, Ibrahim P. Analysis of proteins, polysaccharides, glycosaponins contents of Piper sarmentosum Roxb. and anti- TB evaluation for bio- enhancing/ interaction effects of leaf extracts with Isoniazid (INH). Nat Prod Rad, 2008; 7: 402-408.

Folin O, Ciocalteu V. Tyrosine and tryptophan determination on proteins. J Biol Chem, 1927; 73: 627-649.

Brand-Williams W, Cuvelier ME, Berset C. Use of a free radical method to evaluate antioxidant activity. LebensmittelWissenschaftTechnologie, 1995;28: 25-30.

Lim TY, Lin YY, Yule CM. Evaluation of antioxidant, antibacterial and antityrosinase activities of four Macaranga species. FoodChem, 2009; 114: 594-599.

Voet D, Voet JG, Pratt CW. 2008. Principle of Biochemistry. John Wiley and Sons, Incorporated

Bradford MM. A rapid and sensitive for the quantitation of microgram quantitites of protein utilizing the principle of protein-dye binding. Anal Biochem, 1976; 72: 248-254.

Dreywood R. Qualitative test for carbohydrate material. Ind Eng Chem Anal, 1946; 18: 499.

Yemm EW, Willis AJ. The estimation of carbohydrates in plant extracts by Anthrone. 1954; 57: 508-513.

Rispail N, Morris P, Webb KJ. Phenolic compounds: extraction and analysis. Lotus japonicas Handbook, 2005; 349-355.

Manach C, Scalbert A, Morand C, Remesy C, Jime'nez L. Polyphenols: Food source and bioavailability. Am J Clin Nutr, 2004; 79; 727-747.

Prabhune et al. Free Radical Scavenging (DPPH) and Ferric Reducing Ability (FRAP) of some Commelinaceae members, Int J Bio Pharma App Sci, 2013; 2: 1128-1134.

Padayatty SJ, Katz A, Wang Y, Eck P, Kwon O, Lee JH, Chen S, Corpe C, Dutta A, Dutta SK, Levine M. Vitamin C as an antioxidant: evaluation of its role in disease prevention. J Am Coll Nutr, 2003; 22: 18 35.

De Oliveira AMF, Pinheiro LS. Total phenolic content and Antioxidant of Some Malvaceae Family Species. Antioxidant,2012;33-43.

Chan EWC, Lim YY, Wong LF, Lianto FS, Wong SK, Lim KK, Joe CE, Lim TY. Antioxidant and tyrosinase inhibition properties of leaves and rhizomes of ginger species. Food Chem, 2008; 109: 477-483.

Aruoma OI. Methodological considerations for characterizing potential antioxidant actions of bioactive components in plant foods. Mutation Research, 2002; 523-524: 9-20.

Hensley K, Mou S, Pye QN, Dixon RA, Summner LW, Floyd RA. Chemical versus pharmacological actions of nutraceutical phytochemicals: Antioxidant and anti-inflammatory modalities. Current Topics in Nutraceutical Research, 2004; 2:13-26.

Yang B, Karlsson RM, Oksman PH, Kallio HP. Phytosterols in sea buckthorn (Hippophae rhamnoides L.) berries: Identification and effects of different origins and harvesting times. Journal of Agricultural and Food Chemistry, 2001; 49:5620-5629.

Mazlan NA, Mediani A, Abas F, Ahmad S, Shaari K, Khamis S, Lajis NH. Antioxidant, Antityrosinase, Anticholinesterase and Nitric oxide Inhibition Activities of Three Malaysian Macaranga Species. The Scientific World Journal, 2013.

\section{How to cite this article:}

Wan Nur Atiqah Wan Hassan, Farediah Ahmad, Razauden Mohamed Zulkifli, Mohd Azizi Che Yunus. Antioxidant and tyrosinase inhibition activities of Eurycoma longifolia and Swietenia macrophylla. J App Pharm Sci, 2015; 5 (08): 006-010. 